\title{
A Study on Effect Analysis for Ecological Social Welfare Factors for Psychological Well-being of Foreign Workers in Korea
}

\author{
Myung-Hee Jung \\ Professor, Department of Social Welfare, Jungwon University, Korea \\ jmhsubject@hanmail.net
}

\begin{abstract}
This study investigated ecosystem having influence upon psychological wellbeing of alien workers invited by employment permit system who left work not to adapt them to not only life in Korea but also industry, and helped labor workers to realize them and to be good engineer and/or technician in their home countries.

The study has problems of small number of samples to investigate at 8 places having educational institutions that could not represent all of foreign babor workens in Korea. Investigation into foreign labor workers at other places having no educamonal institutions was needed. Various kinds of networks of foreign labo workers weve expanded to show their desire of activity in Korea. The foreign labo wo kers should be supported to work during limited time and to settle in Korea.
\end{abstract}

Keywords: Social Welfare, Foreign Workens, Psychological Well-being

\section{Introduction}

Con In modern days, people are free to hoye between countries except of some of countries to get information easily owing to development of information, transportation and telecommunication. In the 21 st century society and era of globalization, knowledge, economy and life and deologies have no border to make world life zone.

Since the 1980s. Korea preferred foreign professional workers owing to rapid economic growth, low birth rate and shortage of labor to let so called 3D business hate inferior labor environment and to suffer from chronic manpower shortage. At the end of the 1990s, Indastrial tramee system invited immigrant workers to Korea in order to supplement shortage of labor force at 3D jobs. Since then, foreign labor workers had immigrated to Korea to increase number of immigrant workers rapidly and to let the workers live in Korea for a long time and to build up multi-culture society.

In 1991, the industrial trainee system was blamed very much because of discrimination against foreign workers and human rights, and passage of the Act on Employment Permit System in 1991 assured of foreign labor workers' minimum wage system, employment insurange and industrial accident compensation insurance to admit of foreign labor workers. In 2014, number of foreigners living in Korea reached 1,790,000. Number of illegally staying foreigners was 208,000 in 2014 so that about $11.6 \%$ of foreign workers stayed in Korea illegally. Number of illegal immigrants was more than 160,000 persons in 2010 to increase by 40,000 person during five years, and rapid increase of alien illegal immigrants raised problem of guarantee of labor rights to ask for improvement (Ministry of Justice, 2014).

UN report on the future says that 2 billion to 3 billion persons, one third of total population in the world, are likely to move in 2050 . The 21 st century is said to be an era of immigrant.

The Korean society is likely to suffer from shortage of labor force because of high level of education and life culture, low birth rate, aging population and hate of 3D jobs. 
So, foreign workers should be brought to supplement lack of labor resource (Seol Donghun, 1996). Human resource is thought to be important at labor market. Increase of foreign workers may create social problem (Park Gyeong-tae, 2000). Foreign workers are admitted to be essential and to accept and accommodate them actively.

All of men should be respected regardless of gender, religion and race to be treated respectfully. Regretfully, foreign workers' lives in Korea are far from the ideology. Foreign workers who are members of the society shall be not the ones who are given welfare but members of the community. But, people admit of them from point of view of the social weak. Foreign workers are not strangers but members in the society who live lives with Korean people temporarily. Most of foreign workers who immigrated upon demand of the country were employed at small business to overcome serious shortage of labor force, and they work under poor labor conditions to produce a lot of problems of difficulty of adaptation to different culture at labor market and to create serious problem (Seol Dong-hun, 1996, requoted).

This study investigated ecosystem having influence upon psychological wellbeing of alien workers invited by employment permit system who left work not to adapt them to not only life in Korea but also industry, and helped labor workers to realize them and to be good engineer and/or technician in their home countries.

The study examined problem solving of change of jobs because of psychological uneasiness, depression and stress of lives in Korea as well as lives at work to find out social welfare service programs for foreign labor workers in Korea

\section{Theoretical Background}

\subsection{Adaptation of Foreign Workers in Korea}

The society with high multi-cultural cognition was said to be group that cultural majority group had same value of minority group (Cronin and Taylor, 1992), and to have multi-cultural identity based on mutual understanding, respect, communication and reliability (Vertovec, 1996)

Social distance was prefudice and subjective feeling on various kinds of social groups to apply to empirical study (Bogatdus, 1933). Social distance was applied to racial problem to be understanding and difference between persons (Bogardus, 1933). Social distance was friendliness (subjective distance) that group member thought of another group and to be scope of social contact acceptable.

The society with multi-cultural cognition had racial, cultural and multi demographic phenomenon to cognize social and cultural variety and to have social ideology and to protect social and cultural variety and to let individual to get access to equal opportunity without discrimination against race and nationality and to have government policy and programs (Troper, 1999).

A terminology of social distance being different from existing concept was used to avoid disturbance between subjective judge and objective index on social definition and preasuring on foreigners (Laumann, 1965). The social distance that described an indiyidual's attitude toward person having a position to be subjective distance. The concept emphasized subjectiveness of an individual rather than objective and structural aspect to describe subjective feeling toward special group and/or member. First, Koreans in foreign country in common concept means Koreans living in foreign country. Title of Koreans in foreign country is very much in dispute. Commonly used terminology of Koreans in foreign country means adverb of Koreans in foreign country, at overseas and in each country such as Japan and Germany, and noun of Koreans in foreign country, Korean race, Korean residents, etc is used(Kim \& Youn, 2015).

Korea allowed 60 years old or higher elderly Korean Chinese to visit home town at opening of doors of both countries: Migrants labor workers thought of overcoming of 
poverty at rural areas owing to visit to Korea so that more people wanted to migrate to Korea to be employed in Korea. Korean Chinese occupied large ratio of foreigners migrating to Korea to be a part of the ones who migrated to Korea to find out new opportunity of life(Kim \& Youn, 2015).

Inner-control-oriented workers tend to attribute the consequences caused by any person or partner relationship to themselves. Thus, when a new system is introduced they are likely to have less reluctance and fear than outer-control-oriented workers, because they think it is important to deal with the new system.

A weak but slight correlation exists between the desire for achievement and flextime preference. People who have a higher desire for achievement are willing to consider the new system, especially if significant success is reasonably expected. This result is derived from a reasonable judgment that flextime offers an individual the time for selfdevelopment while the organization benefits from the resulting creativity and performance enhancements. Although not the primary analysis, a high correlation is found between control position and the desire for achievement, which is consistent with the results of previous research (lee, 2012).

\subsection{Ecological Social Welfare Support for Foreign Workers on of Foreign Workers}

In this study, points of view of social service of ecosystem for foreign workers have integrated points of view of individuals and environment to cognize open system between men and social and physical environment and to give balanced point of view for supply of social welfare in favor of foreign workers (Elizabeth M. Tracy, 1990).

This study investigated effects of foreign workers' adaptation to lives in Korea from point of view of ecosystem to find out effective involvement. Precedent studies investigated foreign workers' work places. Preceden studies investigated work place systems of foreign workers, and social welfare involvement in foreign workers in the community have different systetn because of speciar employment, and community welfare systems' social welfare for foreign workers should consider the workers' special system. (Gregory R. Pierce, Barbar a R. Sar ason Rwin G. Sar ason (1996).

Foreign workers' stress at work 'place in Korea may have significant difference depending upon number of foreigners at work place and have no difference at gender and time of stay (Seok Hyun-ho, 1998)

In the 1980s employees in Middle East and their families in Korea cognized 'crisis situation' and family made employee overcome stress in the life in Middle East (Chung Ki-seon, 1986). Foreig norkers' stress at adaptation to life in Korea had sole support system of their emotion-oward family in home country. So, social welfare based on ecosystem is needed tolet foreign workers overcome yearning of home country.

Foreign workers' service direction made change of immigrants' characteristics as well as the workers' situation at time elapse to increase international marriage between foreign workers and Koreans and to rear children in Korea (Park Gyeong-tae, 2000). Foreign workers supporters should take care of rearing of foreign workers' children to support children (Seol Dong-hun, 2000). In this study, not only social welfare of foreign workers but also changes of characteristics of foreign workers should be considered. Foreign workers who arrived in Korea to be employed mostly spend time at work place to have relations with bosses, followers and fellow workers. Studies on foreign workers after 1994 said that the workers lived lives at work place to make friends out of work place and to give information and help and to make social net and to establish community for the purpose of friendliness and help in Korea depending upon races (Elizabeth M. Tracy, 1990), Seol Dong-hun, 1996; Ham Han-hui, 1997; Chung Ki-seon, 1998).

Social support system for foreign workers should be made to let the workers adapt to lives in Korea (Gregory R. Pierce, Barbar a R. Sar ason , Irwin G. Sar ason, 1996). In this study, personal factors, family and society had influence upon foreign workers' lives in 
Korea. This study investigated ecosystem for the worker's mental health to let them adapt to lives in Korea and to promote employment.

\section{Methodologies}

Investigation was done from April 4, 2015 to August 30, 2015. The subject was 976 foreign labor workers (E-9). Questionnaire and interview were used. Eight of Foreign labor worker support centers under Human Resources Development Service of Korea joined the investigation. Questionnaire survey of each educational institute was collected: Self-administered questionnaires were used by using questionnaires translated into language of each country. Six of sub factors of psychological wellbeing, for instance, autonomy, environmental governance, goal of life, self-acceptance, affirmative human relations and personal growth were used. Multi-regression was done with not only dependent variables of sub factors but also independent variables of demographic characteristics, personal systems, social environmental systems.

\section{The Findings}

\subsection{Demographic Variables}

Demographic variables had influence upon sub factors of psychological wellbeing, and gender, spouse, educational background, religious actiyities, economic state and source of the income did upon sub factors of psychological wellbeing.

Table 1. Effects of Demographic Factors upon Sub Factors of Psychological

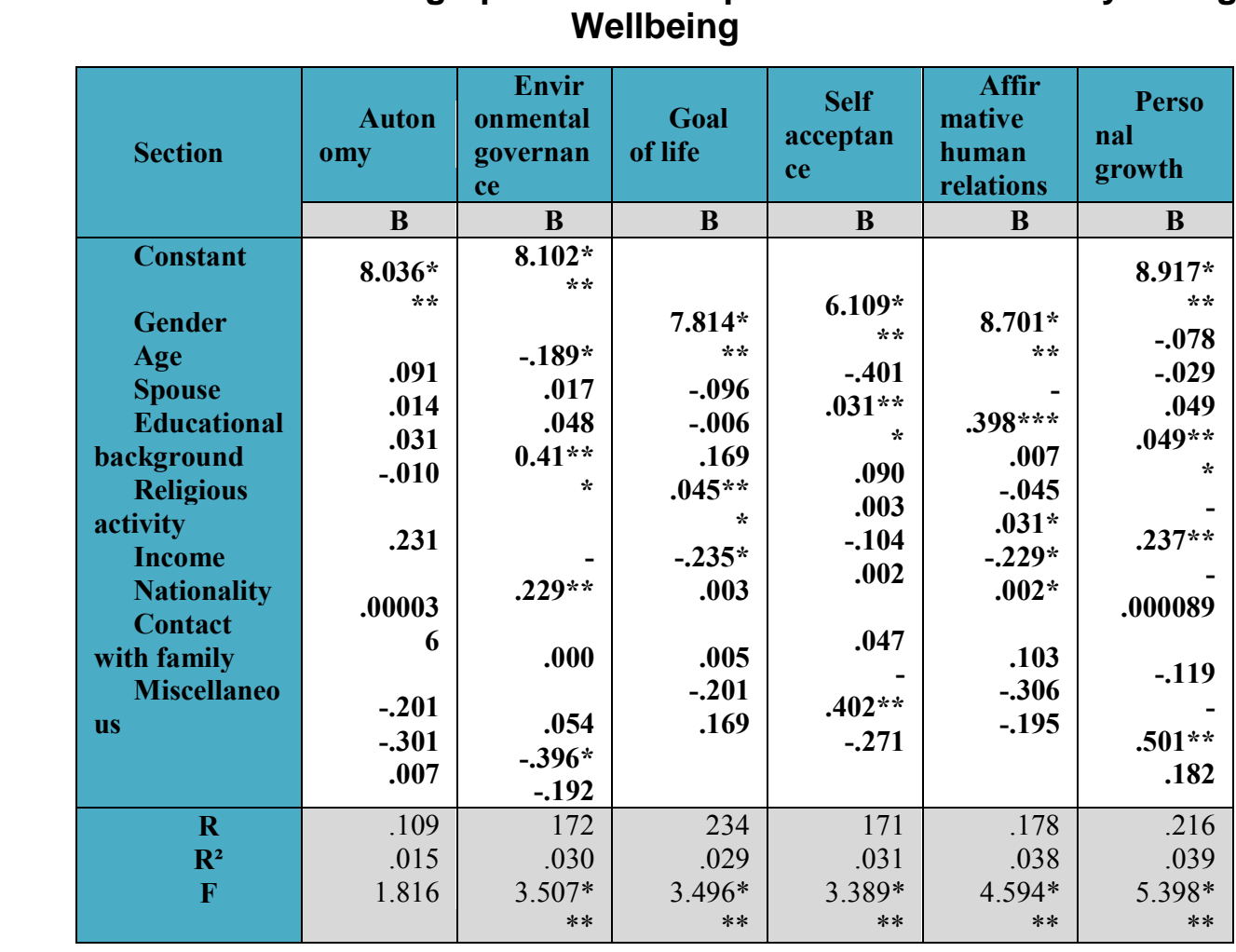

$$
* * * \mathrm{P}<.001, * * \mathrm{P}<.01, * \mathrm{P}<.05
$$

At first, demographic variables had no significant influence upon autonomy that was sub factor of psychological wellbeing. Demographic factors did not influence upon foreign labor workers' selection of job and living life in Korea. Environmental governance factors such as gender $(\beta=-.192, P<.05)$, educational background $(\beta=.041, P<.001)$, 
religious activity $(\beta=-.229, \mathrm{P}<.01)$, and nationality contact with $(\beta=-.402, \mathrm{P}<.05)$ were found to be significant.

\subsection{Sub Factors of Psychological Wellbeing}

The study investigated effects of individual system upon sub factors of psychological wellbeing with independent variables such as subjective state of health, self-esteem, attitude toward the death, contact with family members and family living in same house .

\section{Table 2. Effects of Individual system upon Sub Factors of Psychological Wellbeing}

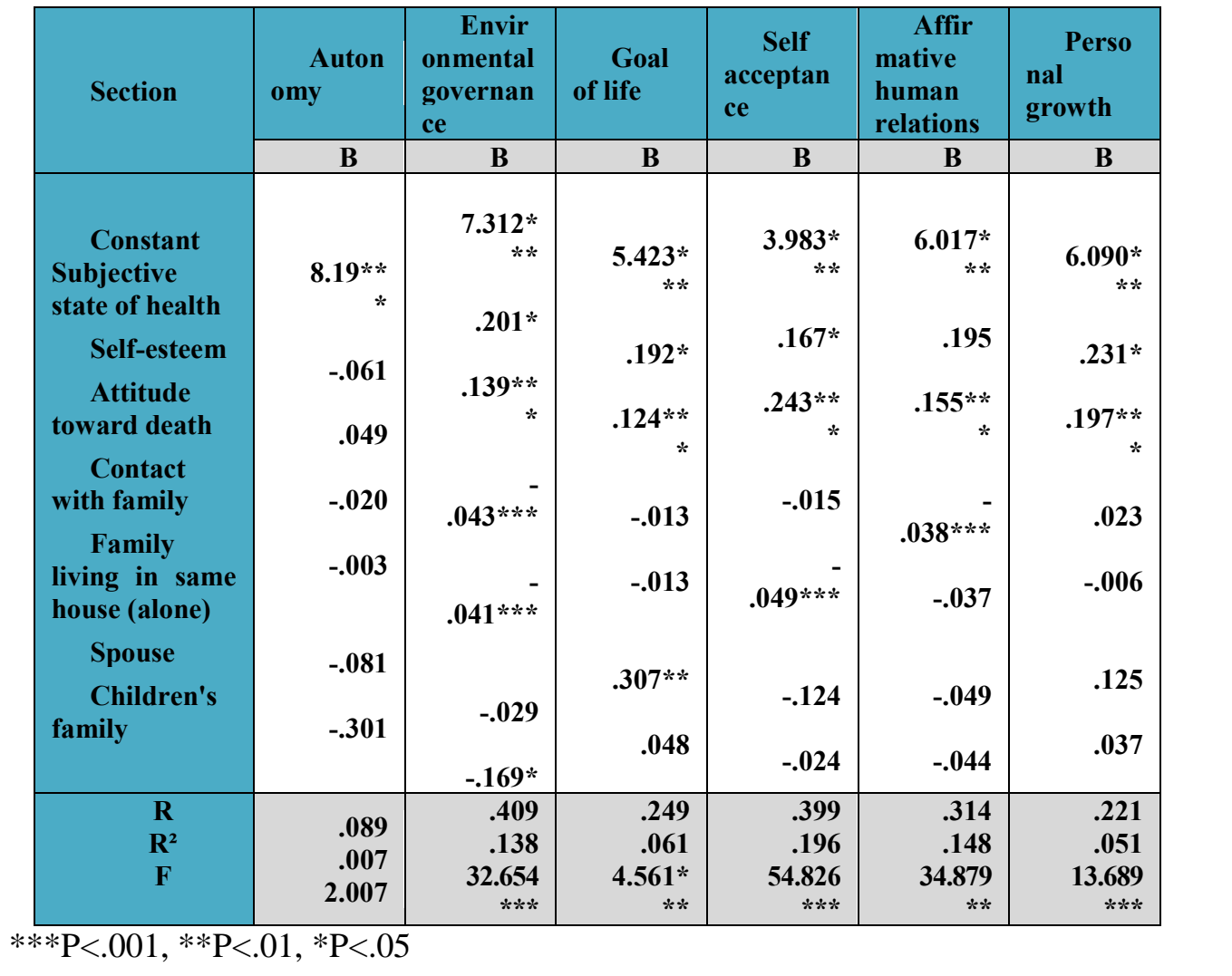

Individual system tariables did not have significant influence upon autonomy of sub factor of psychological wellbeing. Foreign labor workers having high self-esteem had affirmative human relations, and the ones having negative attitude toward the death and less contact with family had less affirmative human relations.

Indi idual system variables had influence upon control of the environment, selfacceptron and affirmative human relation. In other words, foreign labor workers could control their lives by subjective state of health, self-esteem, attitude toward the death, contact with family in home country and family living in same house, and human relations with others had affirmative influence upon self-acception. So, foreign labor workers accepted them under unfamiliar environment, and social welfare service program was needed for the labor workers to create subjective lives and to develop self-esteem from point of view of psychology and to make change of attitude toward the death in affirmative way and to keep good human relations in the work and to improve selfacception, control of the life and affirmative human relations. 


\subsection{Regression Analysis of Effects of Psychological Wellbeing}

Regression analysis of effects of psychological wellbeing was done with independent variables of social activity, social isolation, satisfaction with residing environment, cultural prejudice and social support (Table 3 ).

\section{Table 3. Effects of Social Environment System Variables upon Sub Factors of Psychological Wellbeing}

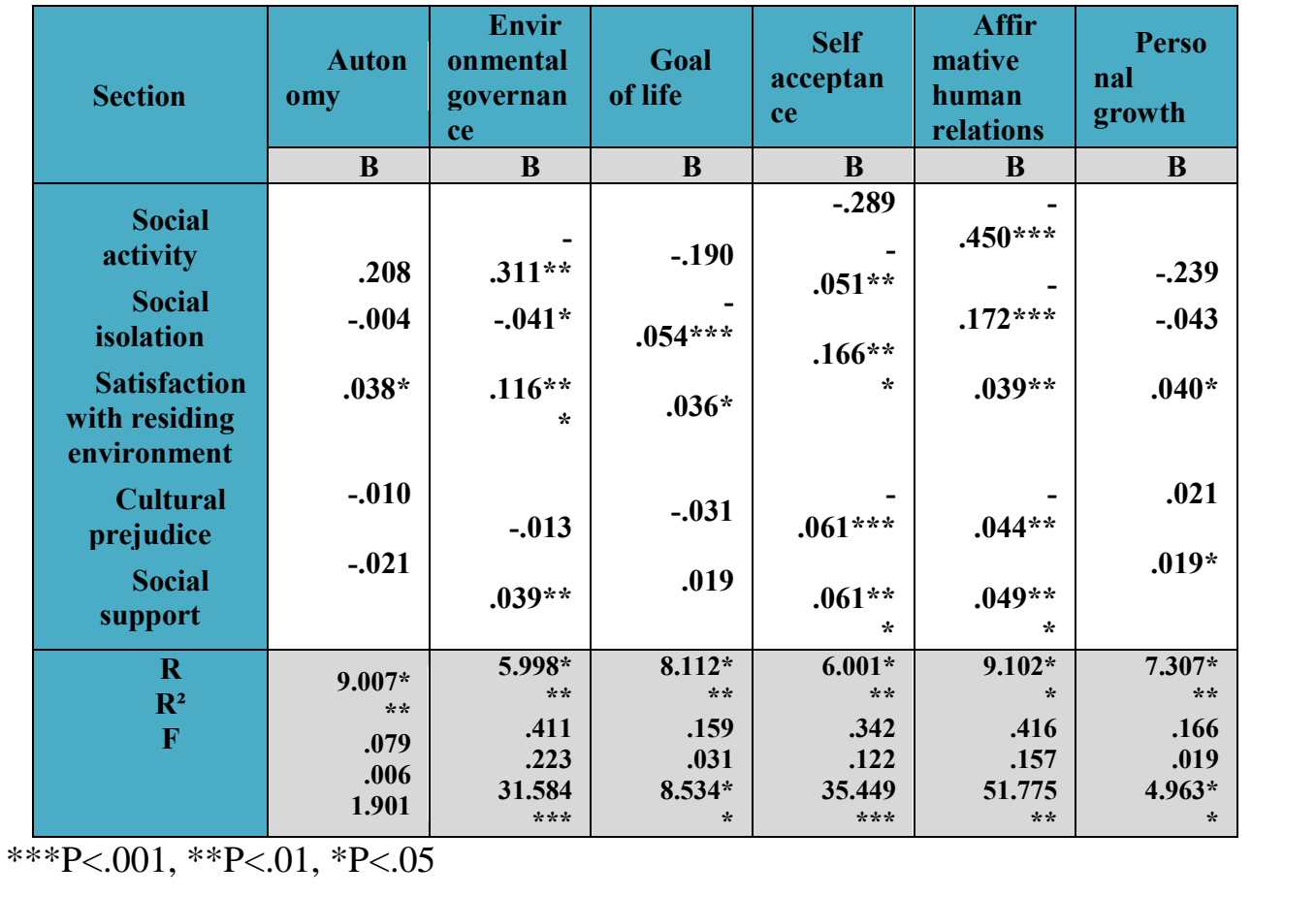

Social environment system variables had influence upon sub factors of psychological wellbeing: The autonomy had influehce upon satisfaction with living environment such as dormitory in the work $(\beta==.038, p<.05)$. Other environmental governance than attitude toward foreigners were significant. Foreign labor workers and their countries seemed to be given cultural prejudice for instance, social activities $(\beta=-311, p<.01)$, social isolation $(\beta=.041, \mathrm{p}<.05)$, satisfaction with living environment $(\beta=.116, \mathrm{p}<.001)$, and social support $((ß=.039, \mathrm{p}<.001)$.

\section{Result and Discussion}

The implleations were:

First, forergn labor workers should be educated to adapt them to Korean culture and to be given social welfare service concerning disorder of adaptation and to produce problems of low productivity, change of work place, and preference to long time illegal immigrant: So, regular consulting for the workers' psychological wellbeing, improvement of cognition on foreign labor workers in the community, and system of not only enterprises but also social welfare resources should be established to support foreign workers at disorder of adaptation.

Second, foreign labor workers' depression, uneasiness, stress and other psychological disorder produced low productivity, changes of work place and illegal immigration so that social connection network for the workers was needed.

Third, administration system of foreign manpower invitation and immigration support was not enough. Many agencies from recruitment of foreign workers to entry into Korea should join to introduce mental test before immigration at increase of complicated and 
long time employment procedure and to let the workers adapt to lives in Korea and to have confidence of human relations at the work.

Fourth, foreign labor workers should lessen labor time to let them take rest and work. Human rights and labor law on foreign labor workers should be adopted in accordance with purpose of employment system to keep service hours as well as break time and to let the workers enjoy at the work and to join self-support meeting of home country and to exchange information and get social support between labor workers.

Fifth, foreigner policy should build up labor market information to let foreigner workers exercise ability and aptitude as much as possible by brokerage system and to learn technology and to do self-realization in enterprises in Korea and to increase selfesteem. Infrastructure should be built up to control foreign manpower and to meet demand on labor market and to put support policy into practice.

The study have problems of small number of samples to investigate at 8 places having educational institutions that could not represent all of foreign labor workers in Korea. Investigation into foreign labor workers at other places having no educational institutions was needed. Various kinds of networks of foreign labor workers were expanded to show their desire of activity in Korea. The foreign labor workers should be supported to work during limited time and to settle in Korea.

Foreign worker's mental health had small number of studies despite importance, and small number of the studies put emphasis uponareas of labor wotkers to neglect individuals, family, jobs, social system and others having influence upon mental health.

\section{Suggestion}

The study investigated factors having inflaence upon foreign workers' adaptation to lives in Korea from point of view of edorystem toffind out the workers' better work places and lives in Korea and to suggest as follow:

Firstly, foreign workers shall be supported to organize a self-supporting meeting. Studies on foreign workers social suppont were: Most of social supports had small support systems that foreign workers thought of very much low support. More social support systems and high social supporthelped foreign workers adapt to lives in Korea significantly. Sociat support system and base should be expanded to help foreign workers adapt to lives in Korea.

Second, foreign workers shal develop information learning to expand their human relations. In Korea, multi-calture family support center and/or foreign worker support center have been open d to help foreign worker get information and to expand human relations. And, foreign workers shall learn the Korean language and use of computer at multi-culture family support center and/or foreign worker support center. But, foreign workers often work on weekend under bad environment to be difficult to learn. So, foreign workers shall be given Hangul program and/or computer program and other programs to get easy access to information and to develop adaptation to lives in Korea.

Third, foreign workers shall exchange information with community residents to lessen racial discrimination and citizens' prejudice. In Korea, the government helped not only foreign workers but also married women immigrants exchange information with citizens on May 20, the day of people in the world. But, understanding on multi culture rather than information exchange was needed to let foreign workers and immigrant understand together with community residents. Information exchange was needed to let them cognize each other like family members. 


\section{References}

[1] Ministry of Justice, "Ministry of Justice Annual Report and Accounts 2014-15”, (2015).

[2] J.J. Cronin and S.A. Taylor, "Measuring service quality: a reexamination and extension", Journal of Marketing, vol. 56, (1992), pp. 55-68.

[3] S. Vertovec, "Multiculturalism, culturalism and public incorporation", Ethnic and Racial Studies, vol. 19 , no. 1 , (1996), pp. 222-242.

[4] E. S Bogardue, "A social distance scale", Sociologt and Social Research, (1933), pp. 265-271.

[5] M. Troper, "La loi Gayssot et la constitution", Annales, no 6, (1999), pp. 1239-1255.

[6] E. Laumann, "Subjective Social Distance and Urban Occupational Stratification", American Journal of Sociology, vol. 71, (1965), pp. 26-36.

[7] C. Delechat, "International Migration Dynamics: The Role of Experience and Social Networks", Labour, vol.15, no. 3, (2001), pp. 457-486.

[8] Granovetter, "The Impact of Social Structure on Economic Outcome", Journal of Economic Perspectives, vol. 19, no. 1, (2005), pp. 33-50.

[9] G.-S. Choi, "Long-term effects of immigrants and invitation of foreign labor workers upon labor market", KDI, (2010).

[10] , G.-J. Yoo and G.-Y. Lee, "State and political subject of foreign labor workers", KDI, (2009

[11] J.-K. P ark, "Social capital and change of job of foreign labor workers in Korea", Doctor degree thesis, Sung Kyun Kwan University, (2013).

[12] H.-D. Cho, J.-K. Hwang and S.-Y. Lee, "A Study on the Aesthetic Art Marketing Communication of Luxury Brand Using Storytelling”, Journal of Distribution Science, vol 9, no.3, (2011), pp. 73-82.

[13] L. Cox, S. Muelle and S. Moss, "The Impact of Entrepreneurship Education on Entrepreneurial Selfefficacy", International Journal of Entrepreneurship, vol.1, no 2 (2002), pp. 286-299.

[14] J. M.mCrant, "The Proactive Personality Scale as a Predictor ofEntrepreneurial nntentions", Journal of Small Business Management, vol. 34, (1996), pp. 42-49.

[15] H. C. Kim and K. W. Hong, "Scale Development of Food Service Business Start-up Reasons and Validity Analysis", Journal of Hotel \& Tourism, vo 29, no.2, (2008) pp. 57-69.

[16] M. S. Kim and Y. G. Kim, "Effect of In ividual Trait, Educational, Organizational Factors on Entrepreneurial Intentions in Tourism College Students: The Meadiating Effects of Entrepreneurial Selfefficacy”, Journal of Foodservice Management Society of Korea) vol.15, no.4, (2012), pp. 61-84.

[17] S. M. Lee, S. B. Lim and R. D. Pathak, "Culture and Entrepreneurial Orientation: A Multi-country Study", International Entrepreneurs ip and Management Journal, vol. 7, no.1, (2011), pp. 1-15.

[18] H. Lee-Gosselin and J. Grise, "Are Women Owner-Managers Challenging Our Definitions of Entrepreneurship? An in-Depth Survey", Journal of Business Ethics, vol.9, no.4, (1990), pp.423-433.

[19] J. H. Lee, "A Study on Entrepreneurial Motivations and Entrepreneurial Decision Makings", The Korean Small Business Ręief, vol.30, no 1, (2008), pp. 93-116.

[20] L. E. McGee, M. Peterson, S. L. Mueller and J. M. Sequeira, "Entrepreneurial Self-efficacy: Refining the Measure", Entrepreneurship Theory and Practice, vol.33, no.4, (2009), pp. 965-988.

[21] M.-S. Park, H.J Kim and S.-Y.Cee, "A Study on the Determinants of Purchasing Decision Making for Effective Branding Strategy: Focusing the Medicined Treatment in Infantile Obesity", Journal of Distribution Science, vol.9. no.3, (2011), pp. 55-64.

[22] J. M. Veciana, M. Aponte and D. Urbano, "University Students Attitudes towards Entrepreneurship: A Two Countries Comparison", International Entrepreneurship and Management Journal, vol. 1, (2005), pp. 165-182.

[23] B. S. Yoon, "Determinate of Entrepreneurial Intention: Individual Characteristics and Environmental Factors", Business Research, vol.17, no.2, (2004), pp. 89-110.

[24] N. S. Yoon, "The Effect of Potential Entrepreneurial Motivations on Entrepreneurship and Commitment to Starts-up: Mediating Role of Entrepreneurship", Journal of Industrial Economics and Business, vol.25, no.2, (2012), pp. 1537-1557.

[25] J.A Hair Jr., R.E. Anderson, R.L. Tatham and W.C. Black, "Multivariate Data Analysis", Prentice-Hall, Sthed., (1998).

C. Anderson and D. W. Gerbig, "Structural Equation Modeling in Practice: 6A Review of Recommanded Two-Step Approach", Psychological Bulletin, vol. 103, no. 3, (1998), pp.411-423.

[27] R. Bagozzi and Y. Yi, "On the Evaluation of Structural Equation Models", Journal of the Academy of Marketing Science, vol. 16, no. 1, (1998), pp.74-94.

[28] R. S. Kaplan and D P. Norton, "The Balanced Scorecard-Measures that Drive Performance", Havard Business Review, (1992).

[29] J. J. Kim and M. K. Youn, "Correlation Analysis of Self-employment of Retirees Using Demographic Characteristics of the Retail Establishment", International Journal of Industrial Distribution \& Business, vol.6, no.4, (2015), pp.17-22.

[30] Lee, Won and Heng, "Distributors' Preference for the Flextime System", Journal of Distribution Science, vol. 10, no.04, (2012), pp.13-20.

[31] G.-T. Park, "Subjects of immigrant workers organization; Research Center of Christian Social Problems of Korea", (2000). 
[32] H.-H. Seok, K.-S. Chung and J.-O. Jang, "Foreign workers' relation with employer and adaptation to the society", A report of As an Foundation. Jip mun dang, (1998).

[33] D.-H. Seol, "Mutual reaction between foreign workers and the Korean society", Volume 13 of Labor problems collection, (1997).

[34] K.-S. Chung, "Foreign worker's social and psychological adaptation", Presentations at latter term contest 1996 of the Society of Sociology, (1996).

[35] K.-S. Chung, "Foreign workers' adaptation to the society and culture", The Korean Society and Foreign Workers, (1998).

[36] H.-H. Ham, "Foreign workers' conflicts and adaptation", Labor problem collections, vol.13, (1997).

[37] E. M. Tracy, "Identifying Social Support Resources of At - Risk Families", In Social Work, (1990).

[38] G. R. Pierce, B.R. Sarason and I.G. Sarason, "Hand Book of Social Support and the Family", PLENUM PRESS, (1996).

[39] N. Lin, X. Ye and W. M Ensel, "Revisiting social support ; Inter gration of it's dimensions", The Chinese Journal of Mental Health, (1999).

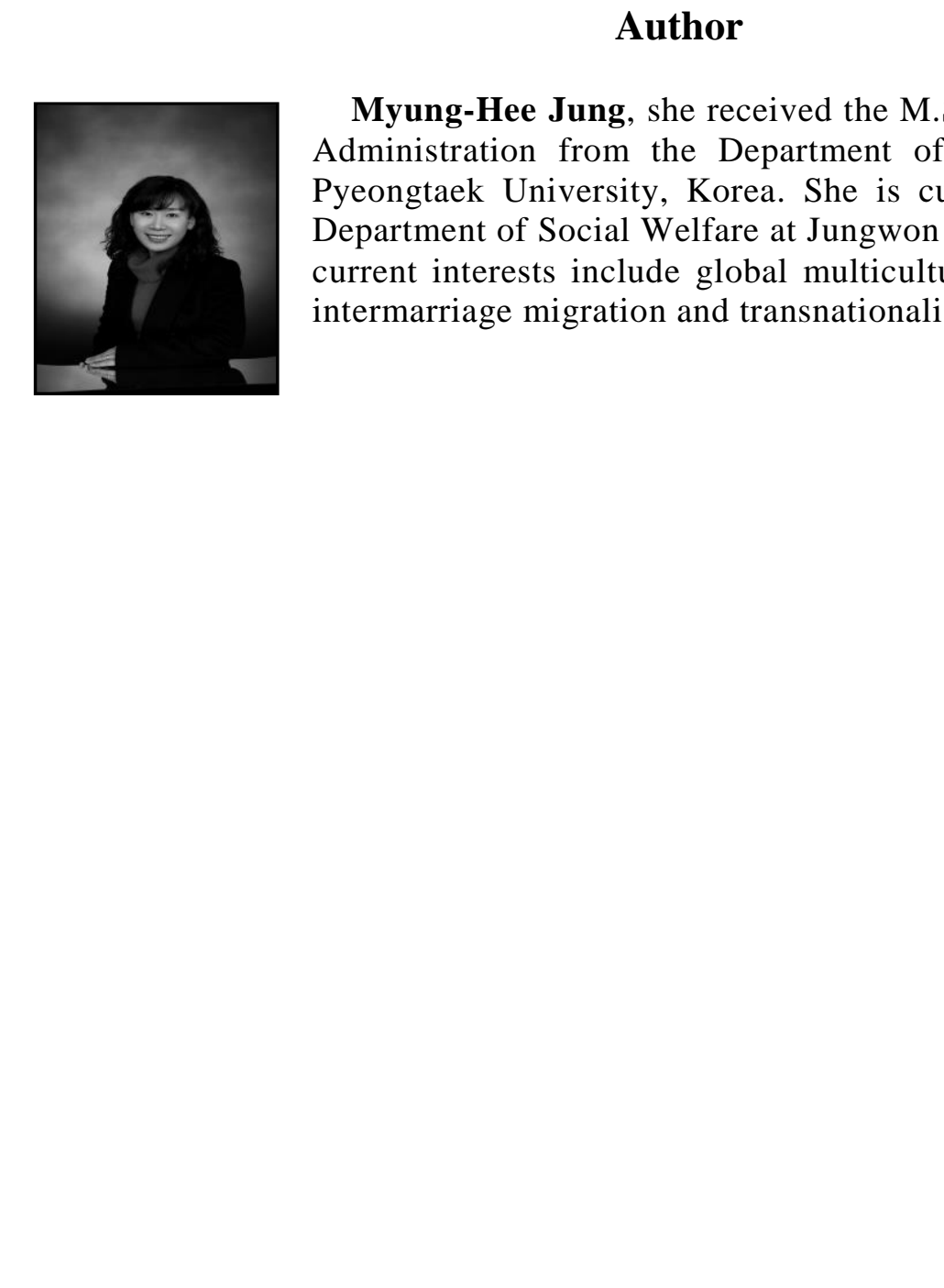


International Journal of Hybrid Information Technology

Vol. 9, No.10 (2016)

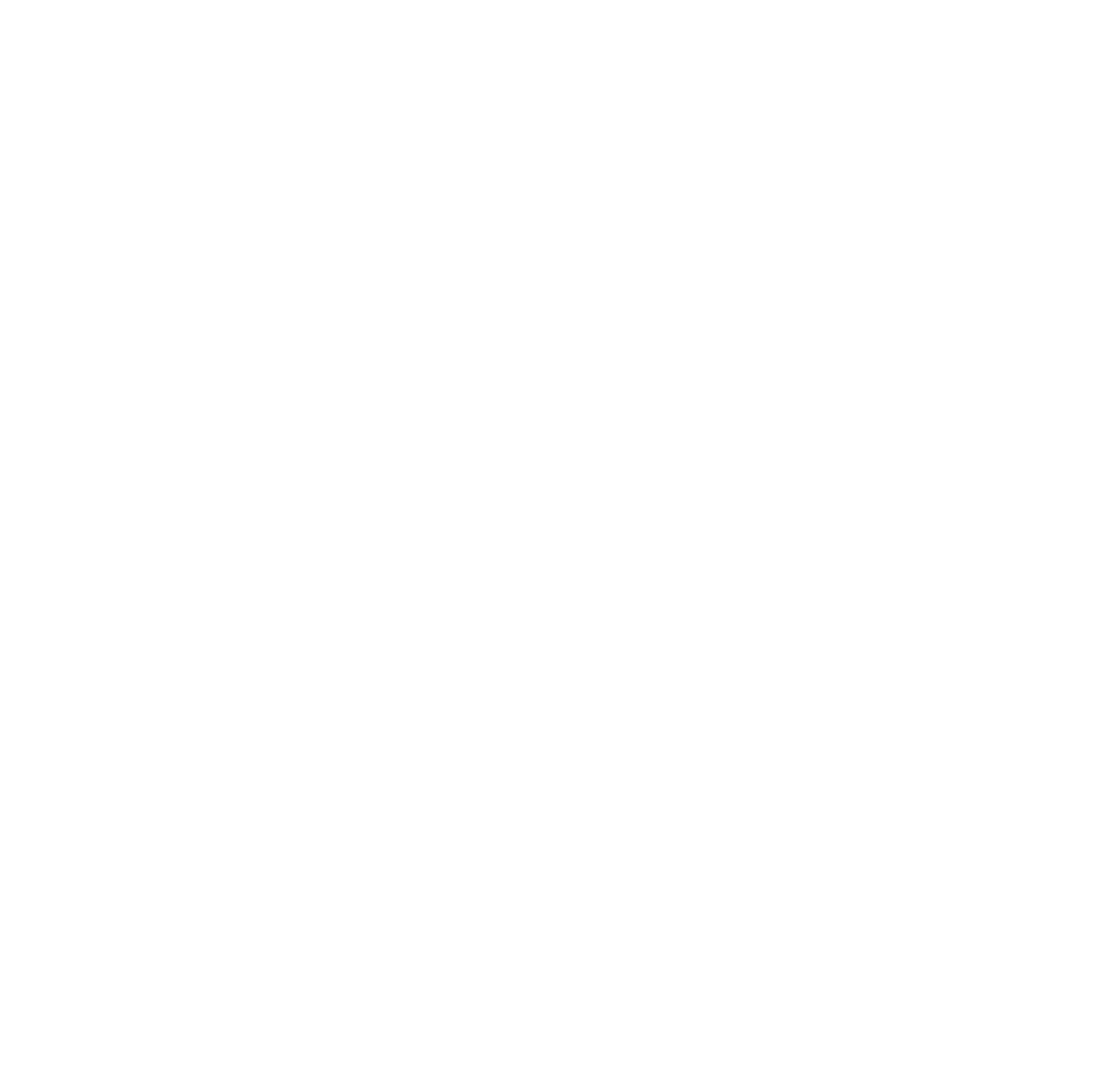

